\title{
Factors affecting food choice in relation to fruit and vegetable intake: a review
}

\author{
J. Pollard*, S. F. L. Kirk and J. E. Cade \\ Nutrition Epidemiology Group, Nuffield Institute for Health, University of Leeds, \\ 71-75 Clarendon Road, Leeds LS2 9PL, UK
}

\begin{abstract}
The present review provides an investigation into the food choice decisions made by individuals in relation to fruit and vegetable consumption. A comprehensive body of evidence now exists concerning the protective effect of fruit and vegetables against a number of diseases, particularly cardiovascular disease and certain forms of cancer. Current UK recommendations are to increase intakes of fruit and vegetables to $400 \mathrm{~g} /$ person per $\mathrm{d}$. In the main body of the review the factors that affect food choice decisions of adults in relation to fruit and vegetable consumption are studied, following a suggested framework of food choice. Factors covered include sensory appeal, familiarity and habit, social interactions, cost, availability, time constraints, personal ideology, media and advertising and health. The content of the review shows just how complex the food choice process can be. Health promotion techniques can be better targeted towards certain groups of individuals, all holding similar sets of values, when making food choice decisions. Food choice, in relation to fruit and vegetable intake, needs to be studied in more depth, in order to provide effective nutrition education programmes, in particular the sets of priorities that different sub-groups of the population consider when making food choice decisions.
\end{abstract}

\section{Food choice: Fruit: Vegetables: Health behaviour}

\section{Introduction}

\section{Background to the review}

Concern about food choices that may have adverse effects on health is currently at the forefront of public health and is embodied in documents such as Saving Lives: Our Healthier Nation (Department of Health, 1999). A comprehensive body of scientific evidence now exists concerning the protective effect of fruit and vegetables against a number of diseases, particularly cardiovascular disease and certain forms of cancer (World Health Organization, 1990). It is the job of the health professional to take this scientific information and adapt it in such a way that

\footnotetext{
Abbreviations: EU, European Union; HDI, healthy diet indicator.

*Corresponding author: Miss J. Pollard, fax +44 113343 3470, email hssjep@leeds.ac.uk
} 
meaningful behaviour change may be achieved by the public. The choices individuals make around foods determine which nutrients are consumed. However consumers do not choose their foods exclusively for the nutrients they provide. Eating behaviour is complex and an understanding of the impact of the factors that affect food choice is vital given the priority for population dietary change.

\section{Aim of the review}

The aim of the present review is to provide a rigorous investigation into the factors affecting the food choice decisions of adults in relation to fruit and vegetable consumption. No such review has been found in the literature. Firstly studies focusing on basic demographic and lifestyle factors affecting fruit and vegetable consumption will be reviewed briefly. Following on from this a theoretical framework will be developed describing the personal, practical, economic and social factors affecting food choice decisions. This framework will form the basis for the main body of the review, which will explore the factors affecting food choice decisions of adults in relation to fruit and vegetable consumption. Finally the implications for health promotion and future research will be considered.

\section{Methodology of the review}

The literature review was conducted systematically. The electronic search strategy was limited to a number of databases, which were the Cochrane Database of Systematic Reviews (CDSR 1997-2001), the Database of Reviews and Effectiveness (DARE 1997-2001), MEDLINE (1990-July 2001), EMBASE, a major biomedical database (1980-July 2001), the Cumulative Index to Nursing and Allied Health (CINAHL 1982-September 2001), PSYCHinfo: Psychological abstracts (1998-July 2001) and the System for Information on Grey Literature in Europe. Within these databases all English-language papers relating to human subjects were sought if the abstracts included any of the following key words: fruit, vegetables or antioxidant nutrients, food choice, health behaviour, health attitudes or eating behaviour. Appetite (1995-2001) was also searched by hand, as this is a key journal within the field. All studies were assessed for relevance and a 'snowball procedure' was employed whereby the references cited in each article were browsed for further relevant research. A total of 494 articles were retrieved and evaluated for relevance.

\section{Demographic and lifestyle factors affecting fruit and vegetable consumption}

It has been recommended that an intake of $400 \mathrm{~g}$ fruit and vegetables should be included in the daily diet to protect against disease (World Health Organization, 1990). Currently in the UK the mean daily intake of fruit and vegetables is $310 \mathrm{~g} /$ person (Ministry of Agriculture, Fisheries and Food, 1999). However there are large variations in intake between regions, social classes and gender, and many differences exist between the highest and lowest consumers of fruit and vegetables.

Studies of regional differences in fruit and vegetable intakes have found that individuals living in Scotland and the North East of England generally consume less than individuals in the Midlands, South West, Wales, London and the South East (Leather, 1995). Differences in 
intakes are even larger between social classes. It has been found that individuals with higher education, income and social status have a higher consumption of fruit and vegetables than those with lower education, income and social class status (Johansson \& Andersen, 1998; McClelland et al. 1998). In the Health Education Authority's Health and Lifestyle Survey of 1993 it was found that the main demographic characteristics that distinguished between low and high fruit and vegetable consumers were age, gender and smoking status (Thompson et al. 1999). It is these demographic characteristics that perhaps exhibit the strongest variations in intakes of fruit and vegetables, with women consuming more fruits and vegetables than men and older adults consuming more than the younger generations (McClelland et al. 1998). A study of a random sample of 9003 British adults found that frequent fruit and vegetable consumption was 'associated with middle age, non-manual socioeconomic groups, non- and exsmokers, 'sensible' drinkers, small households, the south of the country and people with self-assessed 'excellent' or 'good' health' (Whichelow \& Prevost, 1996).

In order to improve the health of the nation fruit and vegetable intakes need to be increased, especially in those groups whose diets are particularly lacking in these important dietary components. However dietary behaviour change is challenging and difficult to achieve both for the individual making the change and for the health professional recommending it. There are many factors, other than health, that affect the food a person chooses to eat. Knowledge of all of these factors, coupled with an understanding of the process of behaviour change, is vital for the successful completion of any dietary intervention to increase the consumption of fruit and vegetables in the UK.

\section{Factors affecting the food choice of adults in relation to fruit and vegetable consumption}

When considering health behaviours, such as eating behaviour, to focus exclusively on demographic variables such as age, social class and ethnicity allows us to describe a population in general terms. Although this might be important it does not allow for the complexities of human health behaviour. Fig. 1 illustrates a number of potential factors, other than demographic variables, relating to the food choice decisions of adults. Other frameworks have been developed that include some or all of these factors in different forms and to differing degrees of complexity. This simplified framework was developed as part of the present review and the review will cover, in depth, those factors illustrated.

\section{Sensory appeal}

Food is not just eaten for its nutrient value; for many people it is a source of pleasure, an enjoyable experience and even a comforting activity (Clark, 1998). The properties of individual foodstuffs, such as taste, texture, quality, smell and appearance, play an important role in whether a person will choose to consume an item.

A number of studies have found sensory factors to be among the most influential in determining eating behaviour. In a pan-European survey, looking at consumer attitudes to food, nutrition and health, when consumers were asked about their influences on food choice behaviour, 'quality' was the most mentioned influence and 'taste' was within the first three mentioned. This was the case for both the European Union (EU) sample and the UK sub-sample (Institute of European Food Studies, 1996a). A Dutch survey ( $n$ 29) used focus group interviews to look at determinants of fruit and vegetable intake. The authors found that, when look- 


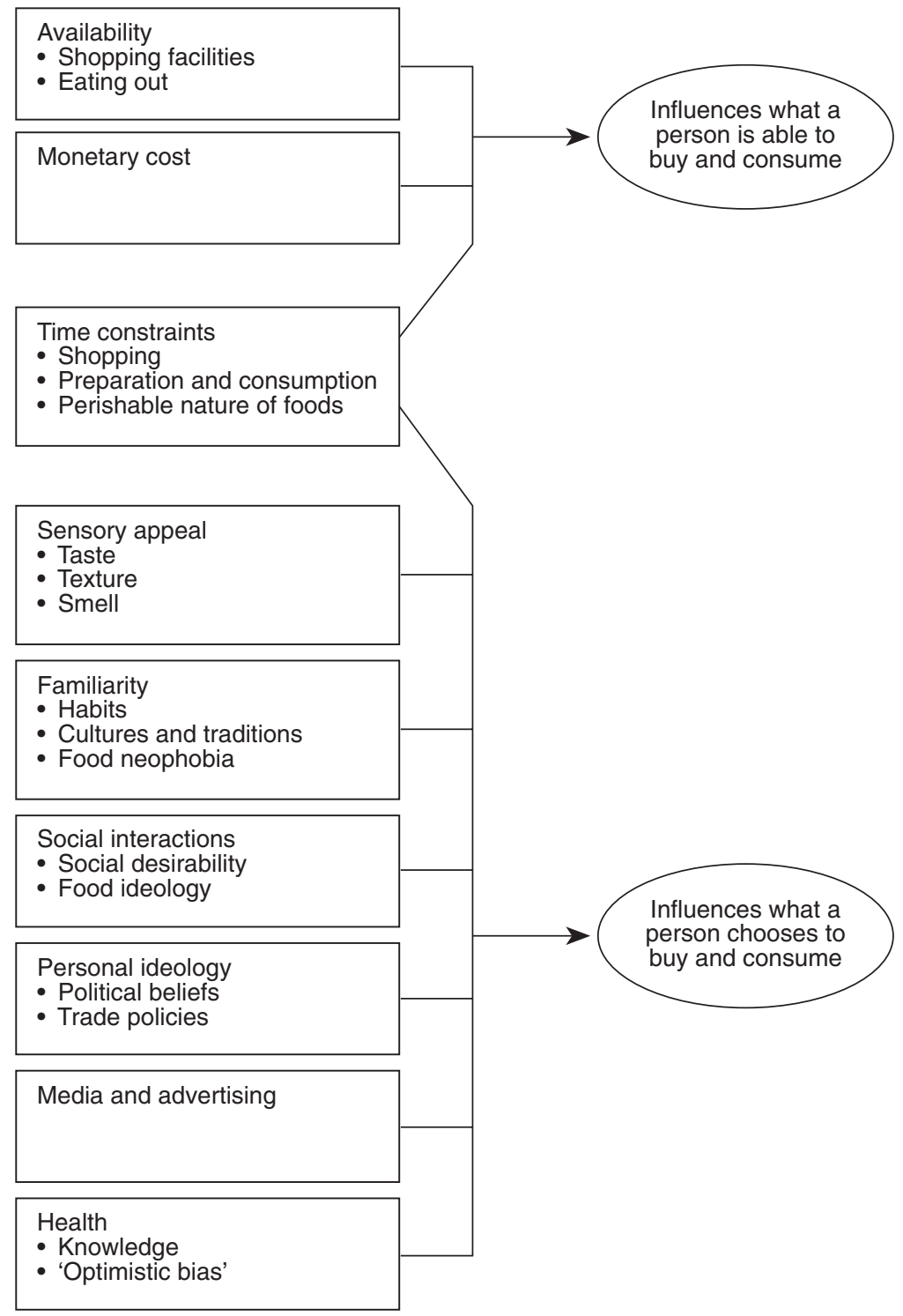

Fig. 1. The food choice framework.

ing at 'satisfaction' beliefs, 'good' taste was an essential prerequisite for the consumption of fruit and vegetables (Brug et al. 1995). Focus group participants in a US study indicated that good taste was perceived as a benefit of increasing fruit intake, although taste was also thought to be a barrier for increasing intakes of the cruciferous vegetables (Heimendinger \& Van Duyn, 1995). This finding is particularly interesting due to the recent work in the area of taste genetics. Individual differences in the ability to taste certain compounds may be one determinant of food rejections. It has long been known that the ability to taste the bitter compounds 6 - $n$-propylthiouracil and phenylthiocarbamide is a genetically inherited trait, and that these substances are 
bitter to some people and tasteless to others (Fischer et al. 1961; Glanville \& Kaplan, 1965). More recently research has found that sensitivity to 6-n-propylthiouracil solutions has been associated with more reported food dislikes. Disliked foods included the cruciferous vegetables; cabbage, Brussels sprouts, broccoli, spinach and kale, as well as grapefruit juice, lemon juice and rhubarb (Drewnowski, 1997). Taste preferences have been shown to influence food choice behaviour (Kaminski et al. 2000), but few studies have examined taste responses, food preference and intake patterns in the same free-living population.

It is uncertain what effect 6- $n$-propylthiouracil taster status might have on current efforts to promote the consumption of cruciferous and green leafy vegetables for health. However it is clear from these findings that sensory responses to taste, smell, sight, and texture of foods are a major influence on both food preferences and eating habits. More research is needed to identify other genes potentially associated with taste response and to investigate their effects on food choice.

\section{Familiarity and habit}

Food habits have been described as 'the way in which individuals in response to social and cultural pressures select, consume, and utilise portions of the available food supply' (Khan, 1981). Food habits evolve from learned experience, which leads to the development of attitudes towards food. Thus food habits become a form of self-expression. It has been said that 'modelling' is an indispensable aspect of the learning process. This was shown to be true in a Dutch study where habit was found to be a strong determinant for the consumption of boiled vegetables, salads and fruit. Subjects stated repeatedly that 'they were eating the way that they were taught at home in the past and continued eating according to those habits when they left their parents to go and live on their own or started their own family' (Brug et al. 1995).

These food habits are the reason why cultures and traditions persist so strongly. It may be said that cultures and traditional practices are the foundations on which all food choice decisions are built. Some of the largest variations in food choice are due to the boundaries laid down by cultures and traditions because they give us values and beliefs in different foods and eating patterns. For many people these provide the framework within which an individual's food choice may evolve. Dietary restrictions play a part in many of the religious and cultural beliefs seen in Britain, although none of these include restrictions on fruit and vegetable intakes. However, some religious groups follow strict diets that, although not necessarily part of the religion, are believed to be beneficial. For example, many Buddhists follow a macrobiotic diet and lifestyle. This diet groups foods into the Yin (expansive) or Yang (contracted) state and diet is used to balance the 'environment, lifestyle and constitution' (http://www. macrobiotic.co.uk/diet.htm, 2001). Vegetables are a particular focus of this diet. Vegetables such as broccoli, leeks and carrots may be used regularly, but restrictions are put on other varieties such as celery, parsnip and peas.

The impact of culture on food choice is immense and varied; however there are still many differences in food choices, and in food likes and dislikes, among members of the same culture (Rozin \& Vollmecke, 1986). The genetic influence of taste has already been discussed, but in the case of food neophobia, that is the initial rejection of novel foods, rejection can be overcome by repeated exposure to and consumption of the novel food item (Koivisto Hursti \& Sjoden, 1997). This suggests that although familial resemblance in food neophobia has been found this is likely to be due to familiarity and habit as opposed to heredity. Some idea is needed about why individuals see some foods as edible, and reject other foods, before food choice behaviour is fully 
understood. The results of a US study carried out with university students $(n 47)$ to investigate the psychological basis of food rejection showed that food rejection behaviour could be categorised into four areas (Fallon \& Rozin, 1983). The authors named these categories as 'distaste', 'danger', 'disgust' and 'inappropriate'. 'Distaste' meant that the person disliked the sensory characteristics of the substance. The 'danger' category was used if the person felt that there would be negative consequences after consuming the food. 'Disgust' was where the person found the idea of eating something offensive and the 'inappropriate' category was used where a person classified a substance as not edible (Fallon \& Rozin, 1983). A Scottish study, using focus group sessions, found that the participants had a strong preference for familiar vegetables and were 'wary' of new varieties (Anderson et al. 1994a). The results of the focus groups were utilised to design a questionnaire that was sent to 1011 adults. The results of this questionnaire discovered that subjects thought that opportunities to try unfamiliar fruits and vegetables in supermarket taste sessions could be a good way to help increase consumption.

\section{Social interactions}

Food is a major focus for social interactions. In one German study it was found that pleasure from food was only partly determined by the sensory aspects of the food items. Factors such as atmosphere, the table, mood and people were all important aspects of the pleasure gained from eating occasions (Westenhoefer \& Pudel, 1993). Many eating occasions occur in company and eating in this way may affect the types and amounts of foods eaten. One study conducted in the UK ( $n$ 5553) discovered that lower consumers of fruit and vegetables had a tendency to consume more of their meals in the living room in front of the television compared with other rooms (Thompson et al. 1999). A second study found that subjects did not 'take the trouble' to prepare boiled vegetables and salads if they were eating alone. If they were preparing food for others, however, this would encourage them to prepare vegetables for the meal (Brug et al. 1995). This could explain the differences in intakes observed in a number of studies between individuals with differing marital status. It has been found that being married is associated with increased fruit and vegetable intakes, whilst being single, separated or divorced may be associated with lower intakes (Billson et al. 1999).

Social pressures have been described in the UK for groups of the population to consume or to avoid certain foods. Results from studies on fruit and vegetables are encouraging. One study found that subjects who thought they consumed high amounts of fruit and vegetables were more positive in attitude and experienced more social influence to consume fruit and vegetables than lower consumers (Lechner et al. 1997). A second study using the Theory of Planned Behaviour (Ajzen, 1991) to predict intention to increase fruit and vegetable intake found that the perceived social pressure to increase consumption was low. However where a social pressure was felt it was positive towards increasing fruit and vegetable intake (Cox et al. 1998).

The large differences in intakes of fruit and vegetables between differing social classes may be due mainly to monetary concerns, but there is some thought that it could partly be due to differing social pressures and interactions. One study, conducted in Sweden, investigated how social networks and social support affected the socioeconomic differences in fruit and vegetable consumption (Lindstrom et al. 2001). The social network variables explored social participation within various formal and informal groups in society and also social anchorage, which dealt with feelings of membership within particular groups. The study found that low social participation was able to explain some of the differences in consumption of vegetables between differing socioeconomic groups (Lindstrom et al. 2001). Perhaps without social par- 
ticipation, and thus social support, it is much more difficult to adapt diet and change to incorporate dietary recommendations. This has been found in the area of obesity management, where a lack of social support was found to be a barrier to successful weight loss (Perri et al. 1993).

The food choice literature commonly refers to the existence of a food 'hierarchy' or food 'ideology', particularly in the UK (Charles \& Kerr, 1988; O’Doherty \& Holm, 1999). The position a food holds within this hierarchy does, to some extent, affect whether or not that food is consumed, particularly in higher socioeconomic groups (Barker et al. 1995). Another part of this food 'ideology', as described by Charles \& Kerr (1988), describes how some foods at the top of the food hierarchy, such as red meat and alcohol, are particularly related to 'maleness' and as such are a symbol of masculinity. Vegetables, however, are seen as women's food and therefore undesirable to men. Although these ideas might seem somewhat out of date the observations are supported by a number of studies throughout Europe. These studies concluded that a greater proportion of the energy consumed by men came from meat, animal products and alcohol, while that of women came from vegetable products and fruit (O’Doherty \& Holm, 1999). Perhaps this food 'ideology' may account for some of the differences found in fruit and vegetable intake patterns between men and women.

The general area of social interactions and food can be summed up by the following quote taken from A Sociology of Food and Nutrition: the Social Appetite (Germov \& Williams, 1999). The authors write '...people can seek to differentiate themselves from others, or alternatively, convey their membership of a particular social group through their food consumption. Ordering a vegetarian meal, eating a meat pie, dining at a trendy café, or eating an exotic cuisine may be used and interpreted as social 'markers' of the individual's social status and group membership'. Social interactions play a huge role in food choice behaviour and these factors need to be taken into account when attempting dietary change.

\section{Monetary cost of food}

The cost of food is a major factor in determining food choice, affecting some groups of the population more than others. A Mintel report on the market drivers of fresh fruit and vegetables (Mintel, 2001a) reports an ongoing shift in the fruit and vegetable market from loose to prepacked, prepared and ready-to-cook products. Over $60 \%$ of the expenditure in the vegetable sector is now on pre-packaged produce. These products are more expensive than loose produce but, according to Mintel, consumers have been ' ... willing to take in the extra cost in a trade off for convenience' (Mintel, 2001a). However there are still some customers who are unable to 'take in the extra cost'. Price, not suprisingly, has been found to be most influential on the food choice of those in lower socioeconomic groups, for example students, the retired and the unemployed (Reicks et al. 1994; Lennernas et al. 1997; Johansson \& Andersen, 1998). It has also been found that those in lower socioeconomic groups consume less fruit and vegetables than those in higher socioeconomic groups (Ministry of Agriculture, Fisheries and Food, 1999; Anderson \& Morris, 2000). One particular study found that recommended foods following UK national dietary guidelines were more expensive than alternative foodstuffs, particularly in deprived areas (Mooney, 1990). Another UK study, set up to investigate direct and indirect costs of a healthy diet, found a healthy diet to be more expensive in monetary terms (Cade et al. 1999). Women were assigned to groups according to where they scored on a healthy diet indicator (HDI). The groups ranged from HDI 0 to HDI 8 , with group 8 having the healthiest diet. Subjects with the healthiest diets spent three times as much on fruit and vegetables than those 
with the lowest healthy diet score. The results showed that the maximum differences in cost



In a study of European subjects a wide geographical variation existed as to the number of subjects who mentioned 'price' as an important barrier to healthy eating. In the overall EU sample $15 \%$ mentioned 'price' as a factor, but UK respondents were at the top end of the range with $23 \%$ of respondents considering 'price' as a barrier (Lappalainen et al. 1997). It has been shown previously and mentioned a number of times within the present review that those in lower socioeconomic groups consume less fruit and vegetables than those in higher socioeconomic groups (Ministry of Agriculture, Fisheries and Food, 1999; Anderson \& Morris, 2000). In order to increase consumption in these groups it is important that intervention messages take price into account. A UK-based study concluded that it would be appropriate to emphasise balancing the perceived higher cost of fruit with less expensive vegetable-based dishes (Anderson et al. 1998). However eating more vegetables, in the form of vegetable-based dishes, does require some degree of skill and probably experimentation with new recipes and varieties of vegetables. In low-income households there is a risk in experimenting with new varieties in case the family do not like them, in which case a replacement meal must be found and this can become expensive. In-store cooking demonstrations and food tasting could provide opportunities for consumers to try new fruits and vegetables at no cost.

Increased imports of fruit and vegetables have meant that year-round availability is now the norm for many varieties of fruit and vegetables. As a result seasonality, once a strong feature of the produce market, is no longer seen as important. However this imported produce has a major effect on the price of products and this could be off-putting for low-income consumers, who feel that fruit and vegetables are more expensive than they necessarily need to be. If consumers are educated into how to find and buy 'in-season' fruit and vegetables this may make purchasing cheaper.

\section{Availability}

This factor relates to the availability of shops, of food within shops and also to the physical effort required to obtain the food. In the 1980s there was a migration of many shopping facilities, including supermarkets, out of city and town centres. This drive has caused many local and smaller retailers within cities to either close down or increase prices. In the year 2000 supermarkets had $83 \%$ of the market share in fresh fruit and vegetables, compared to $11 \%$ for independent greengrocers and $3 \%$ for market stalls (Mintel, 2001a). Once again it is the low-income groups who suffer because it is the local retailers on whom families on low incomes, and those without transport, rely for their weekly food shopping. This means that these families have to either pay higher prices for foods, or pay to use public transport to travel to the new out-of-town supermarkets. Those families without their own means of transport, in 1995, nationally represented a third of all households (Leather, 1995). In relation to fruit and vegetable consumption, theoretically, availability could account for a large proportion of the food choice process. For individuals dependent on public transport or walking to shops, fruit and vegetables are heavy and bulky to carry. Yet for those shopping in local and smaller shops less variety and, for some items, higher prices can be expected. The sheer bulk of food purchased and experiences relating to transport were frequently mentioned factors in one UK study using focus group sessions to discuss increasing fruit and vegetable intakes (Anderson \& Cox, 2000).

Availability affects not only the lower socioeconomic groups. A study that investigated perceived barriers to increasing fruit and vegetable consumption found that the participants 
were finding limited availability of vegetables, salad and fruit at work, when eating out, having take-aways and at friends' houses. This was considered by the participants to be a barrier to increasing intakes (Cox et al. 1998). The same was found in a US study where the women interviewed frequently mentioned difficulties in consuming fruit and vegetables when away from home (Treiman et al. 1996).

\section{Time constraints}

Studies show conflicting opinions on all aspects of time constraints and how they affect food choice decisions. Issues include time available to go shopping and thus the perishable nature of foodstuffs, and also the time available for preparation and consumption of foods and therefore the convenience of foodstuffs. Fruit and vegetables seem to have opposing qualities. A US investigation using focus group interviews found that fruit was viewed as convenient but was considered perishable and expensive when out of season. For vegetables preparation time was considered to be a barrier to increasing consumption (Heimendinger \& Van Duyn, 1995). In a UK study, focus group discussants who were low vegetable consumers saw storage and wastage as a problem, with frozen vegetables as a possible solution, and they also regarded preparation as time-consuming (Kilcast et al. 1996). A second UK study found that participants felt that to increase fruit and vegetable consumption they would have to increase the number of visits made to the shops for food. The same study population also commented that they would need to try more than one retail outlet in order to get the quality they wanted in their fruit and vegetables. Also for individuals who worked throughout the day there were problems with shopping in the evening when fruit and vegetables tended to run out (Anderson \& Cox, 2000).

Among EU subjects 'lengthy preparation' and 'healthy foods being more perishable' were barriers that were not considered to be important, although the main perceived barriers were related to time, including 'irregular work hours' and 'busy lifestyle' (Kearney \& McElhone, 1999). This conflicting evidence is probably due to the fact that time constraints will be more important to some groups of the population than others, for example in the EU sample it was found that younger and more highly educated individuals reported food preparation more frequently as a barrier to a healthy diet (Lappalainen et al. 1997). Some individuals more than others will find their food choice is dominated by their lifestyles. Changes in meal patterns in families, from sitting down to a meal together to more increased frequencies of snacking and 'grazing' in order to fit in around hectic lifestyles, has led to an increase in consumer demand for ready-made and convenience foods. This can be clearly seen in the rise in prepacked and prepared salad and vegetable items in supermarkets (Mintel, 2001a).

It seems then that time constraints are a big issue in food choice and that individuals make constant conscious choices around issues of convenience.

\section{Personal ideology}

Personal ideologies may affect food choice decisions, particularly those of the more affluent consumer (Holt, 1993). Issues surrounding organic produce, genetically modified foods, even down to the type of packaging used can influence an individual's food choice decisions and public concern over food safety issues has been shown to be high (Frewer et al. 1998).

Pesticides are chemical substances used in agriculture for a variety of different purposes, which generally protect plants against damage from pests, insects and the environment. For the 
farmer pesticides have meant higher productivity and yields and for the consumer they have resulted in the better appearance and longer shelf life of many food products. However many consumers are concerned about the accumulation in the body of pesticide residues from foods including fruits and vegetables (National Consumer Council, 1998). Organic fruit and vegetables have been grown without the use of pesticides and this sector of the market has increased dramatically over recent years, despite the rising costs. There was a rise in sales of organic produce in the UK of $40 \%$ between 1998 and 1999 (The Soil Association, 1999), and in the summer of 2000 over one third of adults bought at least some organic produce (Mintel, 2001a). A study commissioned by The Soil Association and Baby Organix found that of the people who do buy organic produce $43 \%$ do so because of preferred taste, $28 \%$ because it is environmentally friendly and $24 \%$ because it is animal-welfare friendly. The study also found that fruit and vegetables were the most commonly purchased organic products (The Soil Association, 1999).

A second area of personal ideology that affects the food choice decisions of a large number of British adults is vegetarianism. There are roughly 4 million vegetarians in the UK, about $7 \%$ of the adult population, and an estimated 5000 individuals a week in the UK become vegetarian. On top of this an estimated 10 million individuals in the UK no longer eat red meat (http://www.vegsoc.org, 2002). One study on ecological eating, food ideology and food choice found that the most significant reason for reducing meat and meat products in the diet was health. However the results showed that strict vegetarianism was strongly connected with animal welfare concerns (Holt, 1993). Other influences on a person's decision to become vegetarian are the quality of the food supply, environmental concerns and the influence of friends (Draper, 1992; Santos \& Booth, 1996; Worsley \& Skrzypiec, 1998).

Personal ideology also incorporates any political beliefs or concerns that individuals may possess and use when deciding what food items to purchase. For example, individuals may boycott certain manufacturers because of their trade policies (Burger, 1997). Many consumers will only buy British or local produce in support of British industry and farming. Also many of the fruit and vegetables in our supermarkets are imported, both in- and out-of-season and travel for many miles before arriving on our plates. This 'travelling' adds costs in terms of higher energy costs in transportation, and social and economic costs to certain food producers, who are producing food for export rather than for themselves (Nestle, 2000).

Some individuals in the UK have strong concerns and opinions on all aspects of personal ideology and the food system, but the higher costs and inconvenience of putting their ideologies into practice means that, for many, food choices based on personal ideologies are not always a practical option.

\section{Media and advertising}

In the UK consumers are exposed to a wide range of messages concerning food, and sometimes nutrition, many of which can be contradictory. Information about diet and food is available from a variety of different sources and the media; for example television, radio, magazines and newspapers are widely used in the UK. According to a pan-EU survey when individuals in the UK look for healthy eating information they go first to magazines, then to television and radio, followed by newspapers, food packaging, health professionals, advertising and finally government agencies (Institute of European Food Studies, 1996b).

A Scottish study found that many individuals have perceptions of fruit and vegetables as being 'boring', 'associated with slimming', 'lacking in taste' and 'old fashioned' (Anderson et al. 1994b). Designers and advertisers know how to subtly market different foods, attaching cer- 
tain connotations to them in order to manipulate consumer tastes (McKee, 1995). The low branding of fruit and vegetables means that they are comparatively poorly promoted, and the money spent on advertising fruit and vegetables is decreasing. In $1996 £ 8.6$ million was spent on the combined media advertising of fresh fruit and vegetables and in 2000 this decreased to just $£ 4.5$ million (Mintel, 2001a). Analysis of snacking behaviour has shown that snack eating has increased, and that most of these snacks are of the 'designer food and drink' variety that have been skilfully promoted by clever advertising. To put fruit and vegetable advertising into context in the same year $£ 25.1$ million was spent on media advertising of vitamin and mineral supplements (Mintel, 2001b) and $£ 35.3$ million was spent on media advertising of crisps and snacks (Mintel, 2001c). Fruit and vegetables have to compete in the marketplace against other products that, as can be seen by these figures, are far more heavily promoted and advertised. Innovative marketing strategies to promote fruit and vegetables are much needed to help in efforts to increase consumption levels. One Scottish study found that $48 \%$ of focus group discussants thought that advertising to encourage higher consumption of fruit and vegetables was a good idea (Anderson et al. 1994a). The image of fruit and vegetables needs to be redesigned using sophisticated marketing techniques to make them more attractive to the consumer.

\section{Health}

For some, health may be an important consideration when making choices about which foods to eat. In the Health Education Authority's health and lifestyle survey, lower consumers of fruit and vegetables were more likely to disagree with the statement 'healthy foods are enjoyable' and more likely to agree with the statement 'I don't really care what I eat' (Thompson et al. 1999). In a study looking at perceived important influences on food choice of adults in the EU ( $n$ 14331) the five most important factors were quality, price, taste, family preferences and trying to eat healthily (Lennernas et al. 1997). A second investigation found that a belief in the health benefits of fruit and vegetables may well increase consumption and found that an individual's concern about nutrition is positively related to their dietary behaviour (Dittus et al. 1995). From these results it might be thought that advertising and encouraging the benefits of increasing fruit and vegetable consumption should result in an increased intake. However as observed earlier (p. 374) this is not happening uniformly across the UK. One explanation for this apparent contradiction could be 'optimistic bias', where individuals believe they are less at risk than a comparable member of society (Weinstein, 2000). This 'optimistic bias' has been seen in many studies and in many other areas of health-related behaviour, for example smoking. One study (n 22043 ) found that $69.3 \%$ of participants thought that their diets were already healthy and thus they had no reason to make dietary changes (Cotugna et al. 1992). Another investigation of European subjects ( $n$ 14 331) reported that $71 \%$ of subjects agreed with the statement 'I do not need to make changes to the food I eat, it is already healthy enough' (Kearney et al. 1997). A third study of a random sample of 741 British adults found that over $50 \%$ felt that they were consuming sufficient quantities of fruit and vegetables even when eating less than two portions/d (Cox et al. 1998). In a study reporting discrepancy between two methods of assessing fruit and vegetable consumption in an adult Dutch population ( $n$ 367), it was found that participants rated their own intakes as much higher than their estimated objective intake (Lechner et al. 1997). Those participants who rated their own intake as high had positive beliefs about fruit and vegetable consumption, experienced positive social influence and had a high perceived self-efficacy. 
Food choice behaviour in sub-samples of the population

All of the factors described in the present review have been found, in previous studies, to play a role in the food choice process in relation to fruit and vegetable intake. The size of the role each of these factors plays, and the relationships between them, will differ from person to person. When making food choices an individual must consider the factors most important to them and make compromises between a number of these factors. The sets of priorities that individuals hold will be unique to each individual. However different groups of individuals may hold similar sets of priorities.

A few studies have attempted to categorise sub-samples of the population according to the factors that affect their food choice decisions (Kirk \& Gillespie, 1990; Stewart \& Tinsley, 1995). However only one such study was found in the literature looking solely at fruit and vegetable intakes and food choice decisions in categories of the population (Kilcast et al. 1996). This study simply divided the subjects into high and low vegetable consumers. The results showed some key attitudinal differences between the two groups. These differences were related to control over family eating habits and how the care-giver approached meal planning and cooking responsibilities. The high consumers of fruit and vegetables tended to feel more in control of family members' eating habits, be more food-focused and more experimental in their food preparation. They also planned ahead more in terms of food preparation and meal planning compared with the low consumers. High consumers of fruit and vegetables tended to have a more positive approach to their families' diet with a higher self-esteem in this area. In contrast low fruit and vegetable consumers seemed to lack control over family members' eating habits and possessed feelings of guilt over the family diet. In comparison to the high consumers, the low consumers of fruit and vegetables seemed not to plan the families' diet and these diets appeared to be more repetitive. In the low consumers group, family members tended to eat different foods at different times thereby sabotaging any attempts to plan meals (Kilcast et al. 1996).

\section{Practical applications of the review}

\section{Application of the review to health promotion}

The content of the present review shows just how complex the food choice process can be when taking into account issues such as sensory appeal, familiarity and habit, social interactions, monetary cost, availability, media and advertising, time constraints and health. When considering fruit and vegetables in the context of food choice we can see that all of these issues, either consciously or unconsciously, will affect whether or not a person decides to consume fruit and vegetables at any particular time or meal event. It can be seen that some of these issues will be more influential than others but that different individuals will have different influences on their food choice motivations. Consideration of the food choice process in relation to fruit and vegetables is particularly important when trying to put into effect coherent and practical dietary advice for the public. Any advice has to be realistic and must take into account, and try and deal with, any personal influences on food choice decisions. Some practical techniques and ideas for health promotion strategies to come from the present review include supermarket fruit and vegetable promotions and taste sessions and more sophisticated and trendy advertising and marketing campaigns for fresh fruit and vegetables. More generally, individuals need to be made aware of their own personal consumption levels of fruit and vegetables in order for health promotion messages to be considered personally relevant. 


\section{Application of the review to future research}

Health promotion techniques can be better targeted towards certain groups of individuals, all holding similar sets of values, when making food choice decisions. In order to provide effective nutrition education programmes food choice in relation to fruit and vegetable intake needs to be studied in more depth, in particular the sets of priorities that different sub-groups of the population consider when making food choice decisions. These sub-groups could be based upon demographic data (for example, men and women), intake data (for example, low and high consumers of fruit and vegetables) or on health behaviour models (for example, stages of change data; Prochaska \& Diclemente, 1984), or a combination of all.

\section{References}

Ajzen I (1991) The Theory of Planned Behaviour. Organizational Behavior and Human Decision Processes 50, 179-211.

Anderson AS \& Cox D (2000) Five a day - challenges and achievements. Nutrition and Food Science 30, 30-34.

Anderson AS, Cox DN, McKellar S, Reynolds J, Lean MEJ, \& Mela DJ (1998) Take Five, a nutrition education intervention to increase fruit and vegetable intakes: Impact on attitudes towards dietary change. British Journal of Nutrition 80, 133-140.

Anderson AS, Lean MEJ, Foster A \& Marshall D (1994a) The Chief Scientist reports ... Ripe for change: Fruit and vegetables in Scotland - current patterns and potential for change. Health Bulletin 52, 51-64.

Anderson AS, Marshall D, Lean ME \& Foster A (1994b) Five a Day? Factors affecting fruit and vegetable consumption in Scotland. Nutrition and Food Science 5, 14-16.

Anderson AS \& Morris SE (2000) Changing Fortunes: changing food choices. Nutrition and Food Science 30, 12-15.

Barker M, Thompson K \& McClean S (1995) Attitudinal dimensions of food choice and nutrient intake. British Journal of Nutrition 74, 649-659.

Billson H, Pryer JA. \& Nichols R (1999) Variation in fruit and vegetable consumption among adults in Britain. An analysis from the dietary and nutritional survey of British adults. European Journal of Clinical Nutrition $\mathbf{5 3}$ 946-952.

Brug J, Debie S, van Assema P \& Weijts W (1995) Psychosocial determinants of fruit and vegetable consumption among adults: results of focus group interviews. Food Quality and Preference 6, 99-107.

Burger I (1997) Some aspects of food choice and availability today. Nutrition and Health 11, 233-238.

Cade J, Upmeier H, Calvert C \& Greenwood D (1999) Costs of a healthy diet: analysis from the UK Women's Cohort Study. Public Health Nutrition 2, 505-512.

Charles N \& Kerr M (1988) Women, Food and Families. Manchester and New York: Manchester University Press.

Clark JE (1998) Taste and flavour: their importance in food choice and acceptance. Proceedings of the Nutrition Society 57, 639-643.

Cotugna N, Subar AF, Heimendinger J \& Kahle L (1992) Nutrition and cancer prevention knowledge, beliefs, attitudes, and practices: the 1987 National Health Interview Survey. Journal of the American Dietetic Association 92,963-968.

Cox DN, Anderson AS, Lean MEJ \& Mela DJ (1998) UK consumer attitudes, beliefs and barriers to increasing fruit and vegetable consumption. Public Health Nutrition 1, 61-68.

Department of Health (1999) Saving Lives: Our Healthier Nation. London: HMSO.

Dittus K, Hillers VN \& Beerman KA (1995) Benefits and barriers to fruit and vegetable intake: relationship between attitudes and consumption. Journal of Nutrition Education 27, 120-126.

Draper AK (1992) Vegetarianism in the UK. PhD Thesis. London School of Hygiene and Tropical Medicine.

Drewnowski A (1997) Taste preferences and food intake. Annual Reviews of Nutrition 17, 237-253.

Fallon A \& Rozin P (1983) The psychological bases of food rejections by humans. Ecology of Food and Nutrition 13, $15-26$.

Fischer R, Griffin F, England S \& Garn SM (1961) Taste thresholds and food dislikes. Nature 191, 1328.

Frewer LJ, Howard C, Hedderley D \& Shepherd R (1998) Methodological approaches to assessing risk perceptions associated with food-related hazards. Risk Analysis 18,95-102.

Germov J \& Williams L (1999) A Sociology of Food and Nutrition: the Social Appetite. Oxford: Oxford University Press.

Glanville EV \& Kaplan AR (1965) Food preference and sensitivity of taste for bitter compounds. Nature 205, 851-853.

Heimendinger J \& Van Duyn MA (1995) Dietary behavior change: the challenge of recasting the role of fruit and vegetables in the American diet. American Journal of Clinical Nutrition 61, 1397S-1401S.

Holt GC (1993) Ecological Eating, Food Ideology and Food Choice. PhD Thesis. Bradford University.

http://www.macrobiotic.co.uk/diet.htm accessed 19/03/2001

http://www.vegsoc.org accessed 15/01/2002 
Institute of European Food Studies (1996a) A Pan-EU Survey of Consumer Attitudes to Food, Nutrition and Health, no. 1. Dublin: Institute of European Food Studies.

Institute of European Food Studies (1996b) A Pan-EU Survey of Consumer Attitudes to Food, Nutrition and Health, no. 2. Dublin: Institute of European Food Studies.

Johansson L \& Andersen LF (1998) Who eats 5 A Day?: Intake of fruits and vegetables among Norwegians in relation to gender and lifestyle. Journal of the American Dietetic Association 98, 689-691.

Kaminski LC, Henderson SA \& Drewnowski A (2000) Young women's food preferences and taste responsiveness to 6n-propylthiouracil (PROP). Physiology and Behavior 68, 691-697.

Kearney KM \& McElhone S (1999) Perceived barriers in trying to eat healthier - results of a pan-EU consumer attitudinal survey. British Journal of Nutrition 81, S133-S137.

Kearney M, Gibney MJ, Martinez JA, de Almeida MD, Friebe D, Zunft HJ, Widhalm K \& Kearney JM (1997) Perceived need to alter eating habits among representative samples of adults from all member states of the European Union. European Journal of Clinical Nutrition 51, Suppl. 2, S30-S35.

Khan MA (1981) Evaluation of food selection patterns and preferences. CRC Critical Reviews in Food Science and Nutrition 15, 129-153.

Kilcast D, Cathro J \& Morris L (1996) Practical approaches to increasing vegetable consumption. Nutrition and Food Science 5, 48-51.

Kirk M \& Gillespie AH (1990) Factors affecting food choices of working mothers with young families. Journal of Nutrition Education 22, 161-168.

Koivisto Hursti U \& Sjoden P (1997) Food and general neophobia and their relationship with self-reported food choice: familial resemblance in Swedish families with children of ages 7-17 years. Appetite 29, 89-103.

Lappalainen R, Saba A, Holm L, Mykkanen H, Gibney MJ \& Moles A (1997) Difficulties in trying to eat healthier: descriptive analysis of perceived barriers for healthy eating. European Journal of Clinical Nutrition 51, Suppl. 2, S36-S40.

Leather S (1995) Fruit and vegetables: consumption patterns and health consequences. British Food Journal 97, $10-17$.

Lechner L, Brug J \& De Vries H (1997) Misconceptions of fruit and vegetable consumption: differences between objective and subjective estimation of intake. Journal of Nutrition Education 29, 313-320.

Lennernas M, Fjellstrom C, Becker W, Giachetti I, Schmitt A, Remaut de Winter AM \& Kearney M (1997) Influences on food choice perceived to be important by nationally-representative samples of adults in the European Union. European Journal of Clinical Nutrition 51, Suppl. 2, S8-S15.

Lindstrom M, Hanson BS, Wirfalt E \& Ostergren PO (2001) Socioeconomic differences in the consumption of vegetables, fruit and fruit juices. The influence of psychosocial factors. European Journal of Public Health 11, 51-59.

McClelland JW, Demark-Wahnefried W, Mustian RD, Cowan AT \& Campbell MK(1998) Fruit and vegetable consumption of rural African Americans: baseline survey results of the black churches united for better health 5 a day project. Nutrition and Cancer 30, 148-157.

McKee F (1995) East of Eden: a brief history of fruit and vegetable consumption. British Food Journal 97, 5-9.

Ministry of Agriculture, Fisheries and Food (1999) National Food Survey 1998. London: The Stationery Office.

Mintel (2001a) Fresh Fruit and Vegetables. London: Mintel International Group Limited.

Mintel (2001b) Vitamins and Mineral Supplements. London: Mintel International Group Limited.

Mintel (2001c) Crisps and Snacks. London: Mintel International Group Limited.

Mooney C (1990) Cost and availability of healthy food choices in a London health district. Journal of Human Nutrition and Dietetics 3, 111-120.

National Consumer Council (1998) Farm Policies and Our Food: The Need for Change. London: National Consumer Council.

Nestle M (2000) Ethical dilemmas in choosing a healthful diet: vote with your fork! Proceedings of the Nutrition Society 59, 619-629.

O’Doherty JK \& Holm L (1999) Preferences, quantities and concerns: socio-cultural perspectives on the gendered consumption of foods. European Journal of Clinical Nutrition 53, 351-359.

Perri MG, Sears SF \& Clark JE (1993) Strategies for improving maintenance of weight loss: Toward a continous care model of obesity management. Diabetes Care 16, 200-209.

Prochaska JO \& DiClemente CC (1984) The Transtheoretical Approach: Crossing Traditional Boundaries of Therapy. Homewood, IL: Dow Jones Irwin.

Reicks M, Randall JL \& Haynes BJ (1994) Factors affecting consumption of fruits and vegetables by low-income families. Journal of the American Dietetic Association 94, 1309-1311.

Rozin P \& Vollmecke TA (1986) Food likes and dislikes. Annual Review of Nutrition 6, 433-456.

Santos ML \& Booth DA (1996) Influences on meat avoidance among British students. Appetite 27, 197-205.

Stewart B \& Tinsley A (1995) Importance of food choice influences for working young adults. Journal of the American Dietetic Association 95, 227-230.

The Soil Association (1999) The Organic Food and Farming Report 1999. Bristol: The Soil Association.

Thompson RL, Margetts BM, Speller VM \& McVey D (1999) The Health Education Authority's health and lifestyle survey 1993: who are the low fruit and vegetable consumers? Journal of Epidemiology and Community Health $\mathbf{5 3}$ 294-299.

Treiman K, Freimuth V, Damron D, Lasswell A, Anliker J, Havas S, Langenberg P \& Feldman R (1996) Attitudes and behaviors related to fruits and vegetables among low-income women in the WIC program. Journal of Nutrition Education 28, 149-156. 
Weinstein ND (2000) Mindset, optimistic bias about personal risk and health-protective behaviour. British Journal of Health Psychology 4, 289-300.

Westenhoefer J \& Pudel V (1993) Pleasure from food: importance for food choice and consequences of deliberate restriction. Appetite 20, 246-249.

Whichelow MJ \& Prevost AT (1996) Dietary patterns and their associations with demographic, lifestyle and health variables in a random sample of British adults. British Journal of Nutrition 76, 17-30.

World Health Organization (1990) Diet, Nutrition and the Prevention of Chronic Diseases, WHO Technical Report Series No 797. Geneva: WHO.

Worsley A \& Skrzypiec G (1998) Teenage vegetarianism: prevalence, social and cognitive contexts. Appetite 30, $151-170$. 


\section{Are you a Registered Nutritionist?}

\section{The Nutrition Society}

The Society's register is part of a framework of activities that set and promote high standards of education and that support professional development in nutrition. The register helps employers, the media and the general public to identify appropriately qualified individuals. Members on the register are expected to adhere to the Society's Code of Ethics. The Nutrition Society's Register replaced the Register of Accredited Nutritionists, run by the Institute of Biology in conjunction with the Society. Individuals who qualified as Accredited Nutritionists transferred to the Society's register in 1999. The Register is published on the Society's website and, from time to time, in printed form.

\section{Register of Nutritionists}

Members of the Nutrition Society have the opportunity to apply for Registration in Nutrition that enables the individual to use the title Registered Nutritionist and the letters $R$ Nutr after their name. Members of the Society who have been working in the field of nutrition for a minimum of three years and who have academic qualifications in nutrition, dietetics or a related subject are eligible to apply. Certain other relevant qualifications may also be acceptable.

\section{Associate registration}

Members with appropriate qualifications who have not worked for at least 3 years after graduating may also apply for registration as Associate Nutritionists. This confers the title Associate Nutritionist and letters Assoc Nutr.

How to Apply

Send a recent $\mathrm{CV}$, photocopied qualification certificate(s) and the names of THREE academic and/ or professional references to the Society's Registrar.

\section{Register of Public Health Nutritionists}

The Society has a policy to develop specialist categories of the general Register to cater for members with specialist expertise. In 1997, the first, a Register of Public Health Nutritionists, was launched. Members of the Society who have been working in the field of Public Health Nutrition for a minimum of three years in the last five and who have appropriate qualifications are eligible to apply. Members who fulfil the criteria for registration are able to use the title Public Health Nutritionist and the letters RPHNutr after their name.

How to Apply

Send a recent CV, photocopied qualification certificate(s) and the names of TWO academic and/or professional references to the Society's Registrar.

\section{Associate registration}

Members who qualify from accredited courses and who have not worked for at least 3 years after graduating are eligible for registration as Associate Public Health Nutritionists. This confers the title Associate Public Health Nutritionist and letters Assoc. PHNutr.

For more information about the Registers, registration fees and about the Accreditation of Courses in Public Health Nutrition contact:

The Registrar, The Nutrition Society, 10 Cambridge Court, 210 Shepherds Bush Rd, London W6 7NJ Fax +44 (0) 207602 1756; Email: mail@ nutsoc.org.uk 